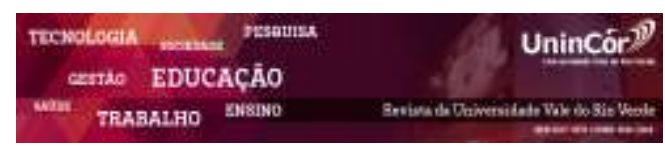

Revista da Universidade Vale do Rio Verde ISSN: 1517-0276 / EISSN: 2236-5362 Vol. 16 | n. 2 | Ano 2018

Fernando Costa Cavalcante Noronha Universidade Federal do Piauí - UFPI fernandonoronha21@gmail.com

Luciano Cavalcante de Jesus França Universidade Federal de Lavras - UFLA lucianodejesus@florestal.eng.br

João Paulo Fernandes Conceição Universidade Federal do Piauí - UFPI jp_fernandes1@live.com

Bruno Ettore Pavan

Universidade Estadual de São Paulo - UNESP brunoe.pavan@gmail.com

Séfora Gil Gomes de Farias Universidade Federal do Piauí - UFPI seflora@gmail.com

\section{GERMINAÇÃO E CRESCIMENTO \\ INICIAL DE PLÂNTULAS DE ESPÉCIES DE DIFERENTES PROCEDÊNCIAS DO GÊNERO Schizolobium spp.}

\section{RESUMO}

Este trabalho foi realizado com o objetivo de avaliar o efeito das diferentes espécies e procedências do gênero Schizolobium na germinação das sementes e crescimento inicial das plântulas. Foram avaliadas duas espécies, sendo elas o $S$. parahyba e o $S$. amazonicum, onde as procedências da primeira foram de Ribeirão Grande - SP e Jaboticabal - SP e as da segunda foram de Belém PA e Dom Elizeu - PA, estado do Acre e Mato Grosso. O delineamento utilizado foi inteiramente casualizado com 4 repetições e 25 sementes por parcela experimental. Foram avaliados no trabalho a porcentagem de germinação, o índice de velocidade de germinação, o índice de velocidade de emergência, porcentagem de sobrevivência, o comprimento da radícula e o comprimento da parte aérea da plântula. A procedência do Acre mostrou-se inferior às demais, em que se pressupõe que a mesma apresente menor potencial para plantio comercial. Das procedências apresentadas, a originada do estado de Mato Grosso foi a que apresentou os melhores resultados.

Palavras-chave: Produção de mudas. Variabilidade genética. Domesticação de plantas. Paricá. Sementes Florestais.

\section{GERMINATION AND INICIAL GROWTH OF SEEDLINGS OF DIFFERENT SPÉCIES PROVENANCES OF GENRE Schizolobium spp.}

\begin{abstract}
This work was carried out to evaluate the effect of different species and origins of the genre Schizolobium spp. seed germination and early seedling growth. We evaluated two species, which were S. parahyba and S. amazonicum where the provenances were the first of Ribeirão Grande - SP and Jaboticabal - SP and the second from Belém - PA, Dom Eliseu PA, State of Acre and Mato Grosso. The experimental design was completely randomized with four replications and 25 seeds per plot. We assessed the work the germination percentage, the index of germination speed, the speed of emergence index, survival percentage, the length of the radicle, and length aerial part of the seedling. The origin Acre proved quite lower than the others, almost always getting the lowest averages, thus being one origin with less potential for a commercial plantation. Already the origin Mato Grosso may have a high potential for commercial plantations, as in three of the characters has proved superior to the others and the remaining is among the largest.
\end{abstract}

Keywords: Seedling production. Genetic variability. Domestication of plants. Paricá. Forest Seeds. 


\section{INTRODUÇÂO}

O Brasil se destaca pelos altos incrementos médios anuais de madeira obtidos em florestas plantadas, juntamente aliadas à capacidade técnica e tecnológica disponível (REIS et al., 2011). Segundo dados da Indústria Brasileira de Árvores (IBÁ, 2016), espécies não convencionais estão sendo muito utilizadas em plantios florestais no Brasil, sendo Seringueira, Acácia, Teca, Paricá, Araucária, Pópulis e outras, corresponderam a 589.201 ha de área plantada em 2015. Dentre essas espécies indicadas para plantios homogêneos, as do gênero Schizolobium destacam-se por apresentarem potencial silvicultural e madeira de qualidade para a fabricação de painéis. É uma espécie de madeira branca cuja distribuição abrange toda a Amazônia brasileira e outros países da América do Sul, que sob condições naturais é encontrada em floresta primária e secundária de terra-firme e várzea alta (VIEIRA, 2006). Sendo no Brasil de ocorrência na Mata Atlântica, o S. parahyba (Floresta Pluvial da Encosta Atlântica) desde a Bahia até o norte do Rio Grande do Sul, a outra espécie é a $S$. amazonicum, com ocorrência restrita à Bacia Amazônica, no Brasil, Bolívia e Venezuela (SOUZA et al., 2003).

Das duas espécies acima citadas, o paricá ( $S$. amazonicum) é uma espécie florestal importante e vem sendo muito utilizada por empresas do ramo, apresentando várias vantagens, como fácil obtenção de sementes, rápido crescimento e boa capacidade de regeneração em áreas alteradas por atividades antrópicas (ROSA, 2006), sobretudo, essa espécie também é promissora para os programas de reflorestamento. Nos últimos anos tem se intensificado o interesse na multiplicação de espécies florestais nativas, devido à ênfase atual para os problemas ambientais, ressaltando-se a necessidade de recuperação de áreas degradadas e recomposição da paisagem (ANDREANI JÚNIOR et al., 2014). Com um aumento da demanda por produtos à base de madeira, e em virtude das dificuldades cada vez maiores na obtenção de matéria-prima proveniente de florestas nativas, a busca por espécies alternativas para produção de lâminas tende a aumentar. No Brasil, em 1995, o consumo dos quatro tipos de painéis o aglomerado/MDP, MDF, chapa de fibra e compensado era de $2.159 \mathrm{mil} \mathrm{m}^{3}$, representando $1,6 \%$ do consumo mundial, em 2005, atingiu 4.806 mil $\mathrm{m}^{3}$, correspondendo a $2,2 \%$ do consumo mundial (BANCO NACIONAL

DO

\section{DESENVOLVIMENTO, 2008).}

Essa espécie possui uma alta qualidade na sua madeira, vitalidade, ampla dispersão, rápido crescimento e uma produção periódica de sementes viáveis (REITZ et al., 1979). Uma das formas de obter maior produção de madeira é através do melhoramento genético, já que assim possibilita-se o aumento da produção sem acréscimos de novas áreas para silvicultura, preservando desta forma, as florestas naturais. Mas para a obtenção de indivíduos melhorados, as primeiras avaliações deverão ser feitas na fase de viveiro, sendo significativa para posteriores avaliações e resultados em campo. Sendo que a produção de mudas 
florestais vem tendo um rápido crescimento, sendo destinadas principalmente para plantios comerciais e na recuperação de áreas degradadas. Contudo, a produção de mudas em viveiros exige uma demanda no desenvolvimento de tecnologias que envolvem a redução nos custos de produção e bom desempenho da muda no campo (BERNARDI et al., 2012).

Para a obtenção de populações melhoradas que atendem as exigências da produtividade florestal depende da capacidade da identificação de genótipos desejados na população sob essa seleção. Uma das estratégias de eficiência comprovada para seleção de genótipos é a combinação de testes de procedências e progênies (SAMPAIO et al., 2000).

A variabilidade entre as populações sempre foi alvo de estudos em diferentes espécies, tendo em vista conhecer e explorar essa variabilidade em programas de melhoramento e conservação genética. Baseando-se nisso, as populações de diferentes origens geográficas apresentam diferenças genéticas que surgiram da adaptação às condições ambientais locais em que vivem (OHASHI et al., 2010).

Dessa forma, o presente estudo teve como objetivo avaliar o efeito das diferentes espécies e procedências do gênero Schizolobium spp. na germinação das sementes e crescimento inicial das plântulas.

\section{MATERIAL E MÉTODOS}

O teste de espécies e procedências, na fase de germinação e crescimento inicial de plântulas, foi desenvolvido em área experimental da Universidade Federal do Piauí, Campus Bom Jesus, localizado no município de Bom Jesus-PI (Figura 1). A cidade de Bom Jesus tem clima Quente de Inverno seco, com estação chuvosa nos meses de novembro a abril. A faculdade está situada na latitude $9^{\circ} 05^{\prime} 03$ " sul, longitude $44^{\circ} 19^{\prime} 38^{\prime \prime}$ oeste e $300 \mathrm{~m}$ de altitude.

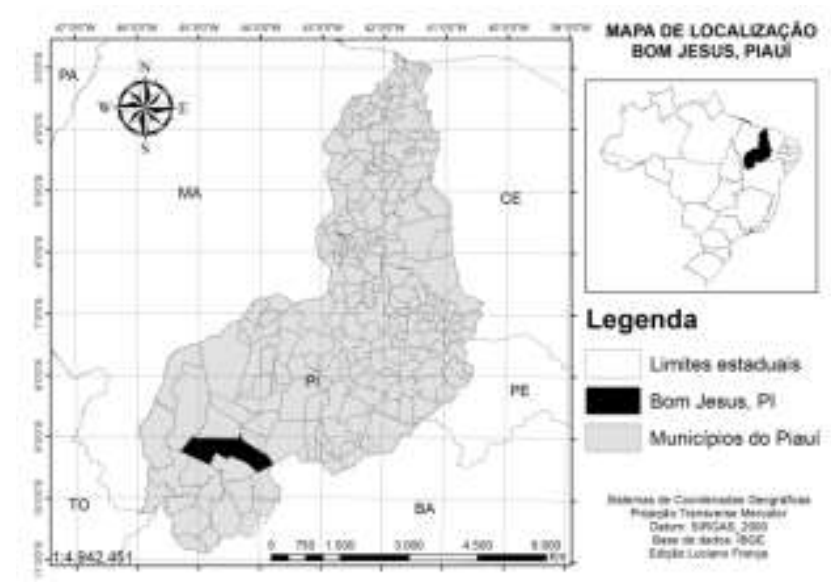

Figura 1 - Mapa Temático de Localização do município de Bom Jesus, Piauí, Brasil.

Foram utilizadas sementes de duas espécies de Schizolobium parahyba (Guapuruvu) e Schizolobium amazonicum (Paricá), onde as procedências da primeira foram de Ribeirão Grande - SP e Jaboticabal - SP e as da segunda foram de Belém - PA, Dom Elizeu - PA, estado do Acre e estado do Mato Grosso. O delineamento experimental utilizado foi inteiramente casualizado com quatro repetições com 25 sementes por parcela e seis tratamentos.

Antes dos experimentos definitivos, foi realizada a triagem das sementes visando descartar aquelas imaturas e deterioradas e as que apresentavam danos tegumentares. As sementes foram escarificadas por corte do tegumento com tesoura de poda na região oposta ao eixo embrionário, visando a superação da dormência. A semeadura foi realizada em bandejas de plástico com $05 \mathrm{~cm}$ de altura, $20 \mathrm{~cm}$ de largura e $27 \mathrm{~cm}$ de comprimento preenchida com areia fina as quais foram acondicionadas em suporte suspenso a $1 \mathrm{~m}$ do solo coberto com tela de sombreamento de $50 \%$ a 80 
$\mathrm{cm}$ das bandejas. A areia utilizada no experimento foi lavada esterilizada e seca ao sol.

Foram avaliados no experimento os caracteres comprimento de radícula (C. RAD) e comprimento da parte área (CA) (com auxílio de régua graduada com precisão de $1 \mathrm{~mm})$. A germinação foi avaliada em porcentagem por parcela experimental, foi considerado nesse experimento como a germinação sendo a emissão da raiz primária. A sobrevivência foi avaliada em porcentagem por parcela experimental, sendo que a sobrevivência foi considerada como plântula viva e sadia 45 dias após a emergência. Para os cálculos da porcentagem de germinação e sobrevivência foram adotadas as seguintes fórmulas:

$$
G E R=\frac{S G}{S T} * 100
$$

em que: GER é a porcentagem de germinação; SG é a quantidade de sementes que germinaram; ST é o total de sementes por parcela experimental.

$$
S O B=\frac{P V}{S T} * 100
$$

em que: SOB é a porcentagem de plântulas sobreviventes ao fim do experimento; PV é número de plântulas vivas e sadias ao final do experimento por parcela experimental; ST é o total de sementes por parcela experimental.

Adicionalmente foram calculados para o experimento o índice de velocidade de germinação (emergência da raiz primária) e de emergência (emergência da plântula) calculados de acordo com Maguire (1962), com as formulas a seguir respectivamente:

$$
I V G=\sum \frac{G_{i}}{T_{i}}
$$

em que: IVG é índice de velocidade de germinação; $G_{i}$ é i-ésimo número de sementes germinadas no iésimo dia; e $T_{i}$ é o i-ésimo tempo em dias.

$$
I V E=\sum \frac{E_{i}}{T_{i}}
$$

em que: IVE é índice de velocidade de emergência; $E_{i}$ é o i-ésimo número de plântulas emergidas no iésimo dia; e $T_{i}$ é o i-ésimo tempo em dias.

Estas fórmulas correspondem à média ponderada do tempo necessário para a germinação, tendo como fator de ponderação a geminação e emergência, ou seja, quanto menor este tempo, maior será a velocidade de germinação.

Para coleta de dados foram realizadas contagens diárias da quantidade de sementes germinadas e da quantidade de sementes emergidas, após 15 dias foram cessadas as contagens, medindose assim o comprimento da radícula e o comprimento da parte aérea. Após o término das contagens e medições foram realizados os cálculos para a obtenção dos dados a serem avaliados. Os dados foram submetidos a análise de variância e comparadas pelo teste F. Adicionalmente foi feita a comparação das médias pelo teste Duncan a 5\% de probabilidade. Todas as análises estatísticas foram realizadas com o auxílio do aplicativo computacional GENES versão 2009 (CRUZ, 2006). 


\section{RESULTADOS E DISCUSSÃO}

Na Tabela 1 apresenta-se o resumo da análise de variância para os caracteres estudados. Os resultados da ANOVA indicaram efeito significativo $(p<0,05)$ entre tratamentos pelo teste $F$ apenas para a característica IVG, e não significativo no tratamento, entre espécies e entre procedências, para comprimento de radícula (C. RAD) e comprimento da parte aérea (CA).

Os valores dos coeficientes de variação ambiental (CV \%) obtidos foram considerados de medianos a altos, de acordo com padrões apresentados por Garcia (1989) baseados em Pinus spp. e Eucalyptus spp., indicando boa precisão experimental, podendo-se, portanto, ter confiabilidade nos resultados obtidos. Apenas o caractere comprimento da parte aérea (CA) apresentou baixo CV\% (4,60). IVG e IVE apresentaram os mais altos CV\% (26,18 e 26,26, respectivamente).

Para os caracteres C. RAD e CA os coeficientes de herdabilidade foram inferiores aos demais caracteres (C.RAD $=54,4$ e CA $=65,0)$, demonstrando que a variabilidade genética para tais características não ocorre entre procedências, sendo difícil obter sucesso com a seleção entre procedências e/ou espécies do gênero estudado.

Tabela 1 - Resumo da análise de variância para os caracteres: porcentagem de germinação (GER), índice de velocidade de germinação (IVG), índice de velocidade de emergência (IVE), porcentagem de sobrevivência (SOB), comprimento de radícula (C. RAD) e comprimento da parte aérea (C. PART. AEREA).

\begin{tabular}{cccccccc}
\hline & & \multicolumn{5}{c}{ QM } \\
\cline { 3 - 7 } Fonte de variação & GL & GER & IVG & IVE & SOB & C. RAD & CA \\
\hline Tratamentos & 5 & $773,86^{* *}$ & $4,27^{*}$ & $1,68^{* *}$ & $10,95^{* *}$ & $0,1536^{\text {ns }}$ & $0,08^{\text {ns }}$ \\
Trat(Esp) & 1 & $208,33^{\text {ns }}$ & $6,99^{*}$ & $0,34^{\text {ns }}$ & $0,16^{\text {ns }}$ & $0,27^{\text {ns }}$ & $0,01^{\text {ns }}$ \\
Trat(proc) & 4 & $915,25^{* *}$ & $3,59^{*}$ & $8,06^{* *}$ & $17,11^{* *}$ & $0,14^{\text {ns }}$ & $0,09^{\text {ns }}$ \\
Resíduo & 18 & 142,22 & 1,06 & 0,36 & 0,91 & 0,07 & 0,028 \\
\hline CV\% & & 14,42 & 26,18 & 26,26 & 13,11 & 12,01 & 4,60 \\
Media Geral & & 82,66 & 3,93 & 2,29 & 7,30 & 2,20 & 3,65 \\
$\mathrm{~h}^{2}$ & 81,6 & 75,18 & 78,5 & 91,6 & 54,44 & 65,0 \\
CVg/CVe & & 1,05 & 0,87 & 0,95 & 1,91 & 0,61 & 0,45 \\
\hline
\end{tabular}

Trat(esp): variância entre as espécies; Trat.(proc): variância entre as procedências; CV\%: coeficiente de variação ambiental; $\mathrm{h}^{2}$ : herdabilidade; $\mathrm{CVg} / \mathrm{CV}$ e: relação do coeficiente de variação genética pelo ambiental.

Já para o caráter IVG tanto as espécies e procedências se diferenciaram, demonstrando que há variabilidade genética entre as populações estudadas. Os coeficientes de herdabilidade encontrado podem ser considerados altos para os caracteres SOB, GER, IVE, IVG, demonstrando que tais características são herdáveis e possível de obter sucesso com a seleção, bem como que a capacidade de germinação é dependente da adaptação da procedência ao local de estudo. Logo, as procedências em que as condições ambientais que mais se assemelham com as do estudo têm maiores probabilidades de se adaptarem.

Uma hipótese que pode ser sugerida para haver baixas $\mathrm{h}^{2}$ e altos $\mathrm{CV} \%$ para os caracteres é que a maioria da variabilidade genética pode estar contida dentro da população e não entre, e esta variância ficou confundida com a ambiental pelo teste não ter contemplado matrizes como fonte de variação. 
Na Tabela 2 está apresentada a comparação das médias pelo teste de Duncan a $5 \%$ de probabilidade, para todos os carácteres houve diferenças estatísticas entre a maioria das procedências. Em termos de IVG, as procedências Dom Elizeu, Belém e Mato Grosso se destacaram com os maiores índices, todas apresentando valores superiores há 3,55 encontrado por FERREIRA et. al, (2007) para espécie guapuruvu. As procedências Belém, Dom Elizeu e Mato Grosso, apresentaram melhores desempenhos tanto para IVG quanto para GER, e para SOB as procedências Belém, Mato Grosso e Jaboticabal tiveram os melhores desempenhos.

Tabela 2. Testes de média para as variáveis: porcentagem de germinação (GER), índice de velocidade de germinação (IVG), índice de velocidade de emergência (IVE), porcentagem de sobrevivência (SOB), comprimento de radícula (C. RAD) e comprimento da parte aérea (C. PART. AEREA).

\begin{tabular}{cccccccc}
\hline Espécie & Procedência & GER & IVG & IVE & SOB & C. RAD & CA \\
\hline Paricá & Belém & $94 \mathrm{a}$ & $4,66 \mathrm{a}$ & $2,85 \mathrm{ab}$ & $84,80 \mathrm{a}$ & $5,06 \mathrm{ab}$ & $13,26 \mathrm{ab}$ \\
Paricá & Acre & $60 \mathrm{c}$ & $2,92 \mathrm{~b}$ & $1,30 \mathrm{c}$ & $20,3 \mathrm{c}$ & $6,62 \mathrm{a}$ & $13,78 \mathrm{a}$ \\
Paricá & Dom Elizeu & $90 \mathrm{ab}$ & $4,82 \mathrm{a}$ & $2,20 \mathrm{abc}$ & $61,6 \mathrm{ab}$ & $3,5 \mathrm{~b}$ & $14,13 \mathrm{a}$ \\
Paricá & Mato Grosso & $95 \mathrm{a}$ & $4,84 \mathrm{a}$ & $3,13 \mathrm{a}$ & $75,9 \mathrm{a}$ & $4,69 \mathrm{ab}$ & $10,75 \mathrm{~b}$ \\
Guapuruvu & Jaboticabal & $85 \mathrm{ab}$ & $3,87 \mathrm{ab}$ & $2,27 \mathrm{ab}$ & $66,7 \mathrm{ab}$ & $2,92 \mathrm{~b}$ & $12,44 \mathrm{ab}$ \\
Guapuruvu & Rib. Grande & $72 \mathrm{bc}$ & $2,45 \mathrm{~b}$ & $1,97 \mathrm{bc}$ & $45,7 \mathrm{~b}$ & $4,56 \mathrm{ab}$ & $13,55 \mathrm{a}$ \\
\hline
\end{tabular}

Médias seguidas pela mesma letra nas colunas não se diferenciam estatisticamente entre si pelo teste de Duncan a 5\% de probabilidade.

No caráter IVG, as procedências Acre e Rib. Grande apresentaram-se estatisticamente distinta das demais procedências, e a procedência Jaboticabal semelhante à Acre e Rib. Grande, assim como com as demais procedências. As procedências Dom Elizeu, Belém e Mato Grosso apresentaram germinação superior a encontrada por NETO et. al. (2007) que identificou germinação em torno de 79\% na região de Belém-PA com sementes de paricá provenientes da mesma região.

No caráter IVE houve diferença estatística comparando as médias pelo teste de Duncan a 5\%. As procedências Belém e Mato Grosso, obtiveram índices de velocidade de emergência maiores que 2,32 encontrado por GHISOLFI et al (2006). Para o índice de sobrevivência, grande parte das procedências apresentaram diferenças estatísticas entre si, havendo diferença significativa superior para a procedência Belém e Mato Grosso, os quais assemelharam-se estatisticamente. Para os parâmetros de C.RAD e C.A, distinguiram-se estatisticamente entre parte das procedências, para C.RAD, a procedência Acre, se sobressaiu quando comparada as demais, já Belém, Mato Grosso e Rib. Grande, apresentaram-se semelhanças estatísticas entre si, e para C.A, a procedência Dom Elizeu, Acres e Rib. Grande, sobressaíram-se. Estas diferenças evidenciam que os fatores climáticos e a variabilidade genética das procedências podem ter influenciado nesses parâmetros. De forma geral, a utilização de procedências mais adaptadas as condições de produções de mudas tendem a render o melhor aproveitamento da área de viveiro, proporcionando maior produção de mudas anualmente e diminuindo dessa forma, os custos fixos da produção de mudas. No entanto, estudos com a incorporação fator de variação árvore matriz devem ser feitos, para poder identificar se a variabilidade genética para tais caracteres é devido a procedências ou progênies, além disso, a continuidade das mudas até o plantio, avaliando 
assim, a qualidade da muda e sua capacidade de estabelecimento e sobrevivência em campo.

A existência de variabilidade genética torna possível a seleção de materiais genéticos mais adaptados a condições ambientais diversas e específicas, sobretudo, para diferentes sistemas de produção ou restauração de áreas.

Na tabela 3, são apresentadas as correlações genéticas entre os seis caracteres analisados, o caráter sobrevivência é altamente correlacionado com IVE, demostrando que as velocidades de emergência das plântulas são fundamentais na sua sobrevivência. Assim, quanto mais rápida é a emergência das plântulas maior a probabilidade de sobrevivência no viveiro. Correlações positivas entre SOB e os caracteres IVG e germinação, ou seja, germinação mais rápida e maiores, também garantem maior sobrevivência. Sementes com maior vigor e capacidade de germinação possibilitam plântulas mais sadias e aptas ao desenvolvimento, garantido assim, boa porcentagem de germinação, maior velocidade de germinação e emergência e, consequentemente, maior sobrevivência. Obteve-se correlações negativas significativas entre os caracteres CRAD e SB evidenciando que a sobrevivência das plântulas é dependente desta possuir menor investimento em crescimento de radícula. Notou-se o mesmo efeito para germinação e CA, percebendo-se que sementes que originam plântulas grandes possuem baixa capacidade de germinação e sobrevivência nas condições de Bom Jesus-PI. Tolfo et al. (2005), em pesquisa realizada com Eucalyptus spp. concluíram que estimativas de magnitudes baixas em caracteres de crescimento e produção indicam a expectativa de pequenos progressos genéticos pela seleção indireta baseada nestes caracteres.

Tabela 3. Correlações genéticas entre seis caracteres tecnológicos de sementes do gênero Schizolobium spp: Índice de velocidade de germinação (IVG), Índice de velocidade de emergência (IVE), sobrevivência (SB), comprimento da radícula (CRAD), comprimento da parte aérea (CA) e germinação (GER).

\begin{tabular}{cccccc}
\hline Variável & IVE & SB & CRAD & CA & GER \\
\hline IVG & $0,7679 * *$ & $0,7164^{* *}$ & $-0,2379^{\text {ns }}$ & $-0,376^{\text {ns }}$ & $0,8962^{* *}$ \\
IVE & & $0,9096^{* *}$ & $-0,1264^{\text {ns }}$ & $-0,6309 * *$ & $0,9293^{* *}$ \\
SB & & $-0,4238^{*}$ & $-0,3637^{\mathrm{ns}}$ & $0,9492^{* *}$ \\
CRAD & & & $0,0391^{\text {ns }}$ & $-0,3566^{\mathrm{ns}}$ \\
CA & & & & $-0,4262^{*}$ \\
\hline
\end{tabular}

ns $* ; * *$ não significativo, significativo a 5 e $1 \%$ pelo teste t.

\section{CONCLUSÕES}

As procedências que apresentam condições ambientais como altas temperaturas aliadas a climas mais secos em seu local de origem apresentaram valores superiores relacionados a germinação. A procedência Acre não se adaptou as condições de Bom Jesus-PI, nessa fase de produção, de forma que a produção de mudas dessa procedência ficaria inviável pelo maior número de sementes necessário a produções exigindo maior tempo de viveiro.

As procedências Mato Grosso e Belém foram as que mais se destacaram para os caracteres, apresentando alta capacidade de germinação exigindo menor tempo de viveiro e com alta sobrevivência das plântulas. 


\section{REFERÊNCIAS}

ABRAF. ASSOCIAÇÃO BRASILEIRA DE FLORESTAS PLANTADAS Anuário Estatístico da Ano base 2010. Brasília: ABRAF, 130 p., 2011.

ANDREANI JUNIOR, R.; MELLO, W. S.; SANTOS, S. R. G.; KOZUSNY-ANDREANI, D. I. Superação da dormência de sementes de três essências florestais nativas. Revista da Universidade Vale do Rio Verde, v.12, n.1, p.470-479, 2014.

\section{BANCO NACIONAL DO}

DESENVOLVIMENTO Setorial (Painéis de madeira no Brasil: panorama e perspectivas. Produtos Florestais. Rio de Janeiro, n.27,p. 121-156, 2008.

BERNARDI, M. R.; SPEROTTO JUNIOR, M.; DANIEL, O.; VITORINO, A. C. T. Crescimento de mudas de Corymbia citriodora em função do uso de hidrogel e adubação. Cerne, Lavras, v. 18 , n. 1, p. 67-74. 2012.

FERREIRA, R.A.; OLIVEIRA, L. M.; TONETTI, O. A. O.; DAVIDE, A. C. Comparação da viabilidade de sementes de Schizolobium parahyba (vell.) blake leguminosa e caesalpinioideae, pelos testes de germinação e tetrazólio. Revista Brasileira de Sementes, v. 29, n. 3, p. 83-89. 2007.

GARCIA, C.H. Tabelas para classificação do coeficiente de variação. (Circular Técnica). Piracicaba: IPEF, 1989. n. 171, 11 pp. 1989.

GHISOLFI, E. M.; EFFGEN, E. M.; MENDONÇA, A. R.; NAPPO, M. E.; SILVA, A. G. Influência do tamanho da semente e tipo de recipiente na germinação de Schizolobium amazonicum (Herb) Ducke. Revista Científica Eletrônica de Agronomia. FAEF, Garça-SP, v. 7, n. 9,7 p. 2006.

\section{INDÚSTRIA BRASILEIRA DE ÁRVORES -} IBÁ. Relatório Ibá 2016. Brasília, 2016.

Disponível em http://iba.org/images/shared/Biblioteca/IBA_Rel atorioAnual2016_.pdf, Acesso em 20/09/2016.

NETO, P.A.S.; ALVINO, F. O.; RAYOL, B. P.; PRATA, S. S.; ESQUERDO, L. N. Métodos para superação de dormência em sementes de paricá (Schizolobium amazonicum Huber ex. Ducke)
(Leguminosae - Caesalpinioideae). Revista

Brasileira de Biociências, Porto Alegre, v. 5, supl. 2, p. 732-734. 2007.

OHASHI, S.T.; YARED, J. A. G.; NETO, J. T. F. Variabilidade entre procedências de paricá Schizolobium parahyba var amazonicum (Huber ex Ducke) Barneby plantadas no município de Colares - Pará. Acta Amazonica, v. 40, n. 1, p. 81-88. 2010.

REIS, C.A.F.; FILHO, E. P. Estado da arte de plantios com espécies florestais de interesse para o Mato Grosso. Documentos/ Embrapa Florestas, v. 215, p. 31-39. 2011.

REITZ, R. KLEIN, R. M.; REIS, A. Projeto madeira do Rio Grande do Sul, Sudesul, Rio Grande do Sul, Ed Corag, 525 p. 1979.

ROSA, L. dos S. Ecologia e silvicultura do paricá (Schizolobium amazonicum Huber ex Ducke) na Amazônia brasileira. Revista de Ciências Agrárias, v. 45, p. 135-174, 2006.

SAMPAIO, P. T. B.; RESENDE, M. D. V.; ARAÚJO, A.J. et. al. Estimativas de parâmetros genéticos e métodos de seleção para o melhoramento genético de Pinus caribaea var. hondurensis. Pesquisa Agropecuária Brasileira, Brasília, v.35, n.11, p. 2243-2253, 2000.

SOUZA, C. R.; ROSSI, L. M. B.; AZEVEDO, C. P.; VIEIRA, A. H. Paricá: Schizolobium parahyba var. amazonicum (Huber ex Ducke) Barneby, Circular Técnica 18, Embrapa, Manaus, 2003.

TOLFO, A. L. T.; PAULA, R. C.; BONINE, C. A. V.; BASSA, A.; VALLE, C. F. Parâmetros genéticos para caracteres de crescimento de produção e tecnológicos da madeira em clones de Eucalyptus. Scientia Forestalis, Piracicaba, n.67, p.101-110, 2005

VIEIRA, A. H. Crescimento de mudas de Schizolobium parahyba var. amazonicum (Hiber ex Ducke) barneby sob diferentes níveis de nitrogênio, fósforo e potássio. Embrapa Rondonia, 2006. 


\section{Fernando Costa Cavalcante Noronha}

Engenheiro Florestal formado pela Universidade Federal do Piauí - UFPI, Campus Professora Cinobelina Elvas CPCE, em Bom Jesus, Piauí, atualmente desenvolve trabalhos no setor florestal privado.

\section{Luciano Cavalcante de Jesus França}

Engenheiro Florestal formado pela Universidade Federal do Piauí - UFPI, Mestre em Ciência Florestal pela Universidade Federal dos Vales do Jequitinhonha e Mucurí (UFVJM) / Universidade do Porto (U.Porto) e Doutorando em Engenharia Florestal pela Universidade Federal de Lavras - UFLA.

\section{João Paulo Fernandes da Conceição}

Engenheiro Florestal formado pela Universidade Federal do Piauí - UFPI, Campus Professora Cinobelina Elvas CPCE, em Bom Jesus, Piauí.

\section{Bruno Ettore Pavan}

Professor Doutor na Universidade Estadual de São Paulo UNESP.

\section{Séfora Gil Gomes de Farias}

Professora Doutora, Universidade Federal do Piauí UFPI, Campus de Bom Jesus. 